\title{
Functional oral nanoparticles for delivering silibinin and cryptotanshinone against breast cancer lung metastasis
}

\author{
Ying Liu ${ }^{\dagger}$, Xingmei Xie ${ }^{\dagger}$, Xuefeng Hou, Junyi Shen, Jiangpei Shi, Haizhen Chen, Yuanzhi He, Zhi Wang \\ and Nianping Feng ${ }^{*}$ (D)
}

\begin{abstract}
Background: Breast cancer lung metastasis occurs in more than $60 \%$ of all patients with breast cancer, and most of those afflicted by it eventually die of recurrence. The tumor microenvironment plays vital roles in metastasis. Modulating the tumor microenvironment via multiple pathways could efficiently prevent or inhibit lung metastasis. Silibinin and cryptotanshinone are natural plant products that demonstrate anti-metastasis effects and modulate the tumor microenvironment via different pathways. However, they have poor aqueous solubility, membrane permeability, and oral bioavailability. Oral drug administration may help improve the quality of life and compliance of patients with breast cancer, primarily under long-term and/or follow-up therapy. Herein, we developed poly-N-(2-hydroxypropyl) methacrylamide (pHPMA)-coated wheat germ agglutinin-modified lipid-polymer hybrid nanoparticles, co-loaded with silibinin and cryptotanshinone (S/C-pW-LPNs). We assessed their oral bioavailability, and evaluated their antimetastasis efficacy in a 4T1 breast cancer tumor-bearing nude mouse model.
\end{abstract}

Results: An in vitro mucus diffusion study revealed that pHPMA enhanced W-LPN mucus penetration. After oral administration, pHPMA enhanced nanoparticle distribution in rat jejunum and substantially augmented oral bioavailability. S/C-W-LPNs markedly increased 4T1 cell toxicity and inhibited cell invasion and migration. Compared to LPNs loaded with either silibinin or cryptotanshinone alone, S/C-pW-LPNs dramatically slowed tumor progression in 4T1 tumor-bearing nude mice. S/C-pW-LPNs presented with the most robust anti-metastasis activity on smooth lung surfaces and mitigated lung metastasis foci. They also downregulated tumor microenvironment biomarkers such as CD31, TGF- $\beta 1$, and MMP-9 that promote metastasis.

Conclusions: Silibinin- and cryptotanshinone-co-loaded pW-LPNs efficiently penetrate intestinal barriers, thereby enhancing the oral bioavailability of the drug loads. These nanoparticles exhibit favorable anti-metastasis effects in breast cancer-bearing nude mice. Hence, S/C-pW-LPNs are promising oral drug nanocarriers that inhibit breast cancer lung metastasis.

Keywords: Functional oral lipid-polymer hybrid nanoparticles, Metastasis, Mucus penetration, Silibinin, Cryptotanshinone, Tumor microenvironment

\footnotetext{
*Correspondence: npfeng@hotmail.com; npfeng@shutcm.edu.cn

${ }^{\dagger}$ Ying Liu, Xingmei Xie contributed equally to this work

School of Pharmacy, Shanghai University of Traditional Chinese Medicine,

1200 Cailun Road, Zhangjiang Hi-Tech Park, Pudong New District,

Shanghai 201203, People's Republic of China
}

\begin{abstract}
Background
Breast cancer metastasis is responsible for high mortality among women worldwide $[1,2]$. The lungs are primary targets in breast cancer metastasis. Moreover, there is a high rate of recurrence in lung metastasis [3]. The tumor microenvironment consists mainly of blood
\end{abstract}

(C) The Author(s) 2020. This article is licensed under a Creative Commons Attribution 4.0 International License, which permits use, sharing, adaptation, distribution and reproduction in any medium or format, as long as you give appropriate credit to the original author(s) and the source, provide a link to the Creative Commons licence, and indicate if changes were made. The images or other third party material in this article are included in the article's Creative Commons licence, unless indicated otherwise in a credit line to the material. If material is not included in the article's Creative Commons licence and your intended use is not permitted by statutory regulation or exceeds the permitted use, you will need to obtain permission directly from the copyright holder. To view a copy of this licence, visit http://creativeco mmons.org/licenses/by/4.0/. The Creative Commons Public Domain Dedication waiver (http://creativecommons.org/publicdomain/ zero/1.0/) applies to the data made available in this article, unless otherwise stated in a credit line to the data. 
vessels, endothelial fibroblasts, immune cells, macrophages, signaling molecules, and extracellular matrix (ECM). The associations between tumor cells and the other components in the tumor microenvironment influence metastasis. Therefore, the components of the tumor microenvironment are, in fact, allies of cancer progression $[4,5]$. Drug delivery systems associated with the tumor microenvironment may enhance anti-metastasis efficiency [6]. Nanocarriers can modulate the tumor microenvironment and inhibit metastasis. Anti-metastasis via conventional chemotherapy often fails as the drugs might induce multiple systemic side effects. Furthermore, the therapeutic agents may be inefficient as they cannot contend with the complex pathophysiology and multiple processes involved in metastasis. Alternative treatments derived from natural plant products could provide enhanced anti-metastatic efficacy while inducing fewer side effects.

Silibinin (SLB) is a flavonolignan derived from the fruit of Silybum marianum (L.) Gaertner. In the tumor microenvironment, SLB [7, 8] inhibits tumor angiogenesis [9] and negatively regulates the epithelial-mesenchymal transition (EMT) [7]. It reduces the interaction between ECM and tumor cells by repressing matrix metalloproteinase (MMP) and vascular endothelial growth factor (VEGF) [10]. Silybin phospholipid complex (Siliphos ${ }^{\circledR}$ ), administered orally to early-stage breast cancer patients, concentrates in breast cancer tissues and appears at low levels in normal tissues [11]. Thus, orally administered SLB can regulate breast cancer tumor microenvironment in vivo. Cryptotanshinone (CT) is a quinoid diterpene derived from Salvia miltiorrhiza Bunge. It induces tumor apoptosis, inhibits cancer cell proliferation, and modulates EMT [12-16]. As breast cancer metastasis is complex, we hypothesized that the induction of antimetastasis via different biochemical pathways could simultaneously augment an anti-metastasis effect. A single formulation, co-loaded with SLB and CT, could accomplish this task. However, these substances may have low solubility, limited intestinal absorption, short elimination time, and poor in vivo bioavailability.

Recently, novel oral anti-cancer and anti-metastasis drug delivery systems have been developed [17-19]. It was reported that several nanocarriers such as maleimidyl-poly(ethylene glycol)-co-poly(e-caprolactone) and poloxamer P188 nanoparticles improve the bioavailability and anti-metastasis efficacy of oral drugs in vivo $[20,21]$. Oral nanocarriers ameliorate the quality of life and compliance of the patients especially under longterm treatment and follow-up therapy [19, 22]. However, the intestinal mucus layer and enterocytes are nanocarrier diffusion and transport barriers. In our previous study, we reported the development of wheat germ agglutinin-modified lipid-polymer hybrid nanoparticles (WGA-LPNs) coated with polyethylene glycol (PEG). The WGA modification promotes in vitro cancer cell uptake via receptor-mediated endocytosis. It targets $N$-acetyl-D-glucosamine and sialic acid on the surfaces of enterocytes and microfold cells. PEGylation augments nanoparticle penetration through the mucus layer and prevents the mucin from binding to WGA [23]. The biocompatible hydrophilic polymer poly-N-(2-hydroxypropyl) methacrylamide (pHPMA) can detach from the surfaces of the nanoparticles so that they are available for absorption and endocytosis [24, 25]. Thus, nanoparticle coatings facilitate mucus penetration without compromising cellular uptake. Hence, we propose that pHPMA could serve as a protective, detachable W-LPN coating.

Herein, SLB and CT were co-loaded into pHPMAcoated W-LPNs (S/C-pW-LPNs) to improve the oral bioavailability and anti-metastasis effects of these drugs. We investigated the mucosal diffusion behavior and cellular endocytosis mode of action and the influence of mucin on endocytosis. We also evaluated the anti-metastasis efficacy of these nanoparticles on 4T1 breast cancer cells and a 4T1 tumor-bearing nude mouse model. We attempted to elucidate the in vivo tumor microenvironment alteration mechanism of S/C-pW-LPNs in terms of angiogenesis, epithelial-to-mesenchymal transition, and ECM remodeling.

\section{Results \\ Preparation and characterization of $\mathrm{pW}$-LPNs}

The pW-LPNs were prepared as shown in Fig. 1a. The LPNs were developed using a modified nanoprecipitation technique that encapsulated SLB and CT. The W-LPNs were formed via WGA-DOPE insertion and coated with hydrophilic, biocompatible pHPMA polymer.

The $\mathrm{pW}$-LPNs had greater hydrodynamic diameters than the LPNs (Fig. 1b). Transmission electron microscopy (TEM) revealed that the pW-LPNs were spherical (Fig. 1c). X-ray powder diffraction (XRD) analysis determined SLB and CT encapsulation in the nanoparticles by detecting crystalline changes. Figure $1 \mathrm{~d}$ indicates that pure SLB and CT were highly crystalline and had numerous diffraction peaks. The pure CT had distinctive peaks at $9.0^{\circ}, 9.8^{\circ}, 12.1^{\circ}, 17.2^{\circ}, 24.9^{\circ}, 27.3^{\circ}$, and $29.8^{\circ}$, whereas pure SLB had distinctive peaks at $14.6^{\circ}, 17.5^{\circ}, 19.6^{\circ}, 22.3^{\circ}$, and $24.5^{\circ}$. For the mixture, certain peaks were weak because physical mixing may have altered the crystalline properties of SLB and CT. The absence of SLB and CT peaks in the pW-LPNs suggested that the SLB and CT dispersed within the nanoparticles might be in amorphous or molecular form and/or in a disordered crystalline phase. 


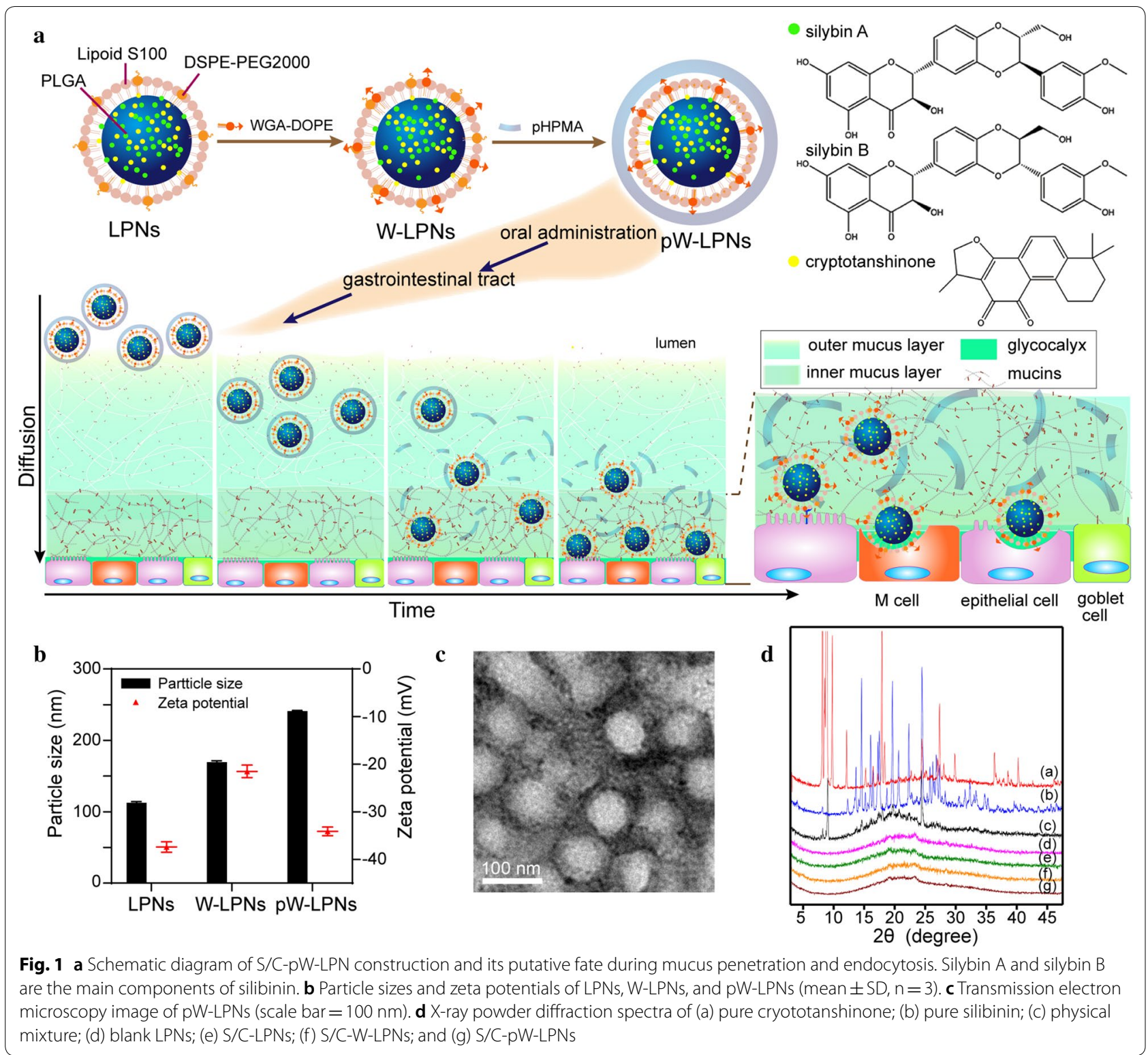

\section{pHPMA enhanced W-LPN diffusion through mucus}

pW-LPN diffusion was performed using a silicon tube rotation test to evaluate the ability of pHPMA to enhance nanoparticle mucus penetration (Fig. 2a). Figure 2b shows that $\mathrm{pW}$-LPNs were distributed throughout the segments, whereas W-LPNs were distributed only in the first segment.

Nanosight tracking assay was conducted using quantum dot (QD)-labeled nanoparticles to establish whether the enhancement of mucus penetration was associated with the interactions between nanoparticles and mucin and the underlying mechanism.
This procedure was performed to avoid intrinsic fluorescence interference. Mucin-free pW-LPNs and W-LPNs exhibited normal, narrow size distributions mainly $<300 \mathrm{~nm}$ (Fig. 2c). After incubation with mucin for $30 \mathrm{~min}$, the peak particle size of W-LPNs increased from $96 \mathrm{~nm}$ to $194 \mathrm{~nm}$ and the size distribution range expanded. In contrast, the pW-LPNs had relatively narrower particle size distributions. Moreover, the concentration and intensity of W-LPNs particles > $300 \mathrm{~nm}$ were higher than those of pW-LPNs, possibly because of agglomeration and adhesion of W-LPNs to mucins and other components. The results suggest that these nanoparticles had different mucin binding capacities 


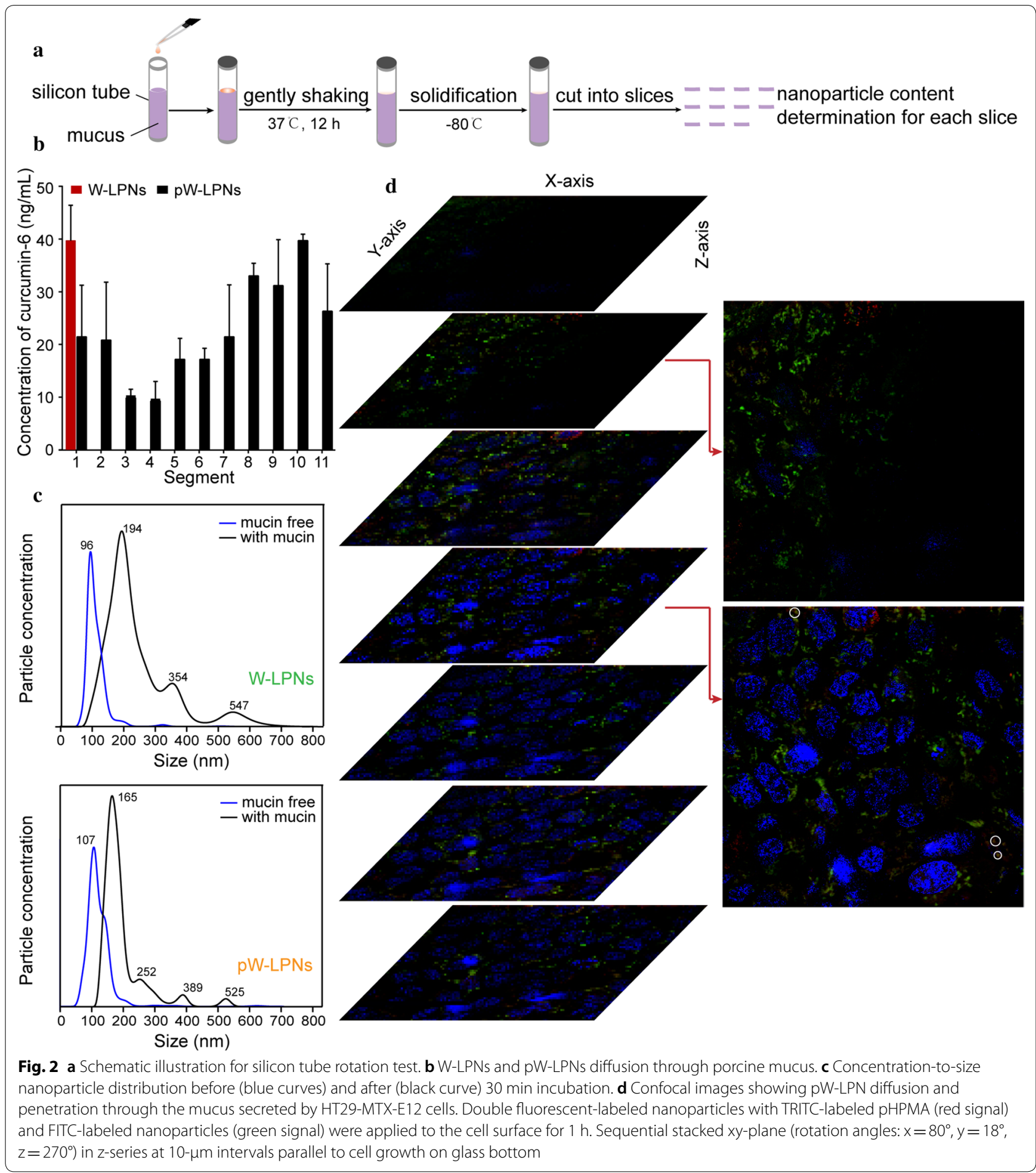

and the presence of pHPMA reduced mucin binding and facilitated nanoparticle diffusion through the mucus.

Confocal laser scanning microscopy (CLSM) was performed to investigate $\mathrm{pW}$-LPN distribution and diffusion behavior through the mucus layer formed by HT29MTX-E12 (E12) cells double-labeled with tetramethylrhodamine (TRITC)-labeled pHPMA and fluorescein isothiocyanate (FITC)-labeled W-LPNs. Micrographs on the $x y$-plane were arranged in $\mathrm{z}$-series tiers at a $10-\mu \mathrm{m}$ 
step depth. Figure $2 \mathrm{~d}$ shows the stacked rotated images. The second image represents the location at $\sim$ tens of micrometers from the nucleus. The clear and strong red and bright green fluorescent signals indicated that pHPMA detached from the nanoparticles. The fourth image represents the inner side of the cell and shows bright green signals indicating that the pHPMA-free nanoparticles were widely distributed throughout the cytoplasm. However, W-LPNs associated with pHPMA sporadically appeared (white circle). Hence, pHPMA could detach from the W-LPNs during mucus layer diffusion. After penetration through the mucus layer, the nanoparticles were exposed to the cell membranes, which led to absorption. In the subsequent cellular uptake study, endocytosis of W-LPNs was evaluated.

\section{Cellular uptake}

Cellular uptake rates are shown in Fig. 3a. The W-LPN fluorescence intensities in Caco-2/E12 co-culture cells (3:1) were higher than those in the LPNs. After removal of mucus with $N$-acetyl- $L$-cysteine, the W-LPN fluorescence intensities were greater than the LPNs. This finding aligned with that of a previous report [26] and indicated that WGA modification might enhance cellular LPN uptake.

The influence of mucin on cellular W-LPN uptake was investigated by loading mucin labeled with FITC and Nile Red into W-LPNs and visualizing cellular uptake using CLSM (Fig. 3c). The images reveal intracellular free FITC-labeled mucin distribution. For the W-LPNs with mucin, green and red signals were distributed around the nucleus. Thus, the cells may have internalized W-LPN-mucin agglomerates. For the cells subjected to W-LPNs preincubated with mucin, the Nile Red fluorescence intensity was more potent than the mucin-free W-LPNs. It should be noted that Nile Red may stain the lipid components, and quantitative analysis was conducted to detect the influence of mucin on cellular uptake. The quantitative analysis of cellular uptake showed that at a mucin concentration range of 0.025-0.1\%, mucin preincubation enhanced W-LPNs uptake, whereas cellular W-LPN uptake efficiency was not concentration-dependent (Fig. 3b). Further, W-LPNs preincubated with $0.5-1 \%$ mucin presented with cellular uptake comparable to that of mucin-free W-LPNs.

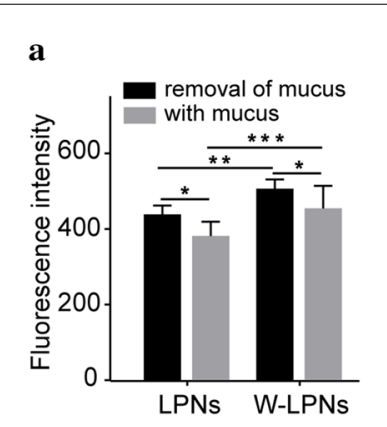

d
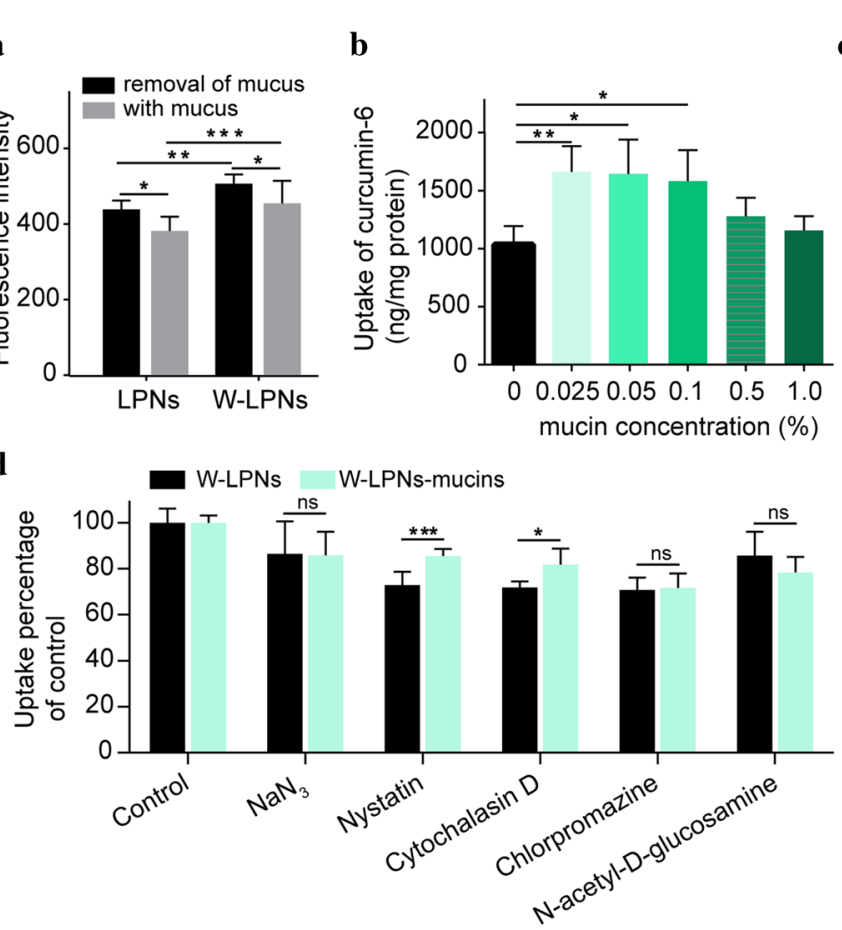

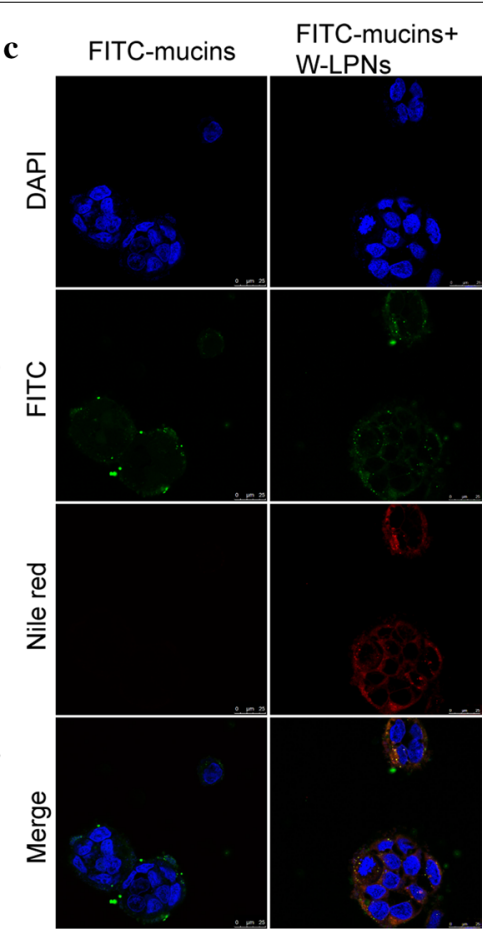

Fig. 3 a Cellular uptake of LPNs and W-LPNs in a Caco-2/HT29-MTX-E12 co-culture with or without mucus treatment with N-acetyl-L-cysteine. b Quantities of coumarin-6 absorbed per milligram cellular protein in Caco-2 cells treated with WGA-LPNs after co-incubation with mucin at various concentrations. c Confocal microscopy images of Caco-2 cells treated with FITC-labeled mucins and WGA-LPNs after incubation with FITC-labeled mucins. Rows 1-4 show the DAPI channel, fluorescein isothiocyanate (FITC) channel, tetramethylrhodamine isothiocyanate (TRITC) channel, and merged images, respectively. $\mathbf{d} \%$ uptake of WGA-LPNs or WGA-LPN-mucins by Caco-2 cells vs control in the presence of different inhibitors (mean $\pm \mathrm{SD}, \mathrm{n}=5) .{ }^{*} P<0.05,{ }^{* *} P<0.01,{ }^{* * *} P<0.001$ 
To elucidate the endocytosis mechanism, we compared the cellular uptake of mucin-free W-LPNs and those preincubated with mucin in the presence of the endocytic pathway inhibitors sodium azide $\left(\mathrm{NaN}_{3}\right)$, nystatin, cytochalasin D, and chlorpromazine. As endocytic pathways are generally energy-dependent, cellular uptake was evaluated in the presence of the energy-depleting agent $\mathrm{NaN}_{3}$. Figure 3d shows that the relative cellular W-LPN uptake with or without mucin decreased by $85.8 \pm 10.1 \%$ and $86.4 \pm 1.2 \%$, respectively. Nystatin inhibits caveolar endocytosis [27]. Here, it impeded W-LPN uptake with and without mucin preincubation. Cellular uptake of W-LPNs preincubated with mucin was significantly higher than that of W-LPNs without mucin pretreatment $(P<0.001)$. Cytochalasin D inhibits micropinocytosis-mediated endocytosis [27]. It considerably reduced W-LPNs preincubated with or without mucin and lowered the inhibitory action of W-LPNs preincubated with mucin compared to that of W-LPNs preincubated without mucin. Cellular uptake of W-LPN preincubated with and without mucin was blocked by chlorpromazine treatment. $N$-acetyl- $D$-glucosamine (NAG) was used as a competitive inhibitor of WGA binding to Caco-2 cells. NAG reduced cellular W-LPN uptake in the presence and absence of mucin. Further, WGA receptor-mediated endocytosis occurred.

\section{Cell viability assay and in vitro anti-metastasis study}

The cytotoxicity of S/C-W-LPN, S-W-LPN, and C-WLPN in $4 \mathrm{~T} 1$ cells was determined using Cell Counting Kit 8 (CCK-8, Sigma-Aldrich Co., MO, USA) assay. As shown in Fig. 4a, the cells treated with $75 \mu \mathrm{g} / \mathrm{mL} \mathrm{S-W-LPNs}$ had $>80 \%$ viability. The $\mathrm{IC}_{50}$ for C-W-LPNs and S/C-WLPNs were $8.30 \mu \mathrm{g} / \mathrm{mL}$ and $5.94 \mu \mathrm{g} / \mathrm{mL}$, respectively.

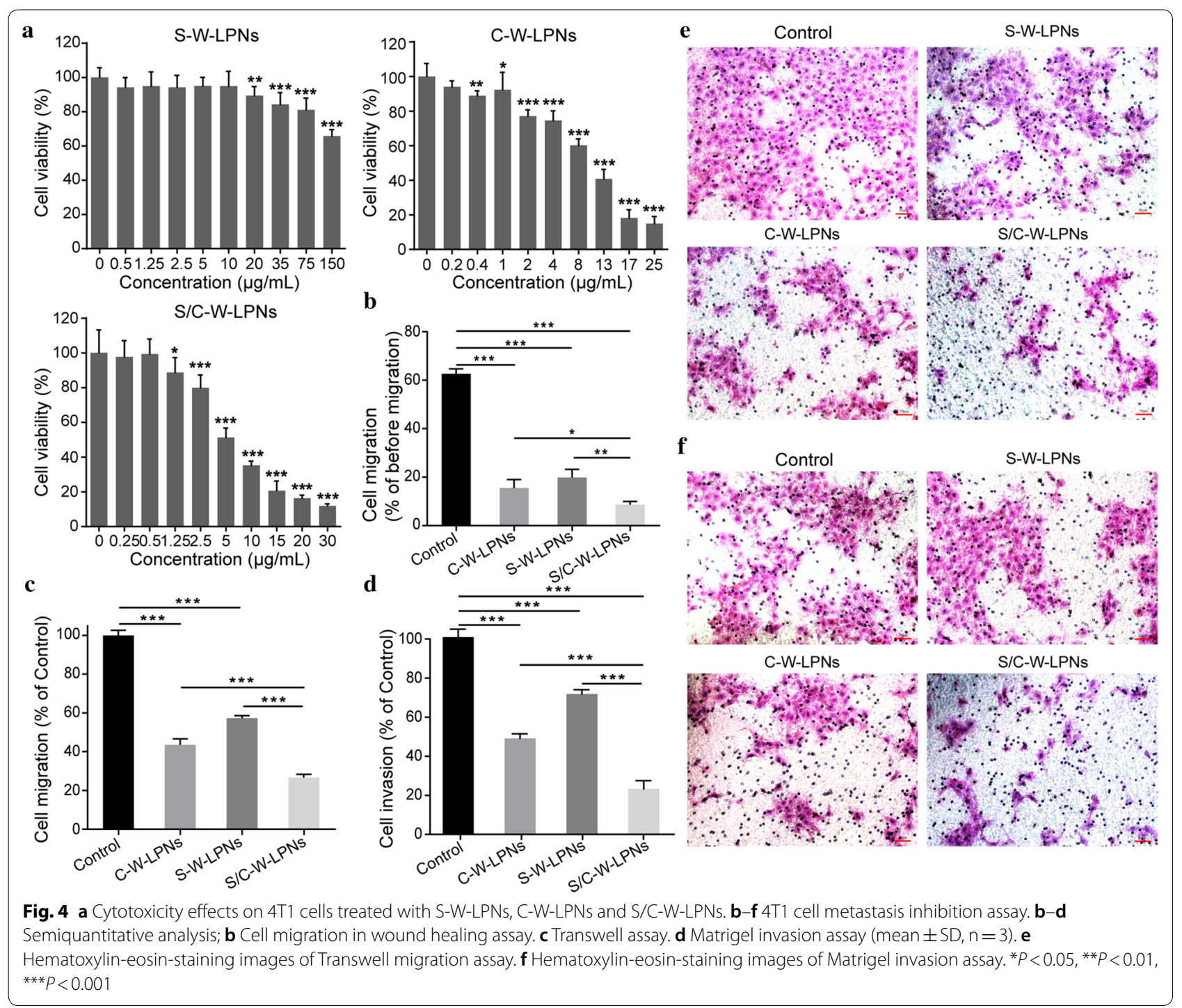


The anti-metastatic effects of SLB/CT-coloaded W-LPNs were evaluated by determining the motility and interactions of highly metastatic 4T1 cells with C-W-LPNs, S-W-LPNs, and S/C-W-LPNs. After treatment with C-W-LPNs, S-W-LPNs, and S/C-W-LPNs, the relative cellular migration rates were $15.5 \pm 3.58 \%$, $19.9 \pm 3.35 \%$, and $8.6 \pm 1.38 \%$, respectively (Fig. 4b).

A Transwell migration assay was conducted to confirm the effects of S/C-W-LPNs on longitudinal 4T1 cell motility. Figure $4 \mathrm{e}$ reveals that relative to the control, 4T1 cells treated with C-W-LPNs, S-W-LPNs, and S/C-W-LPNs presented with considerably less migration activity. Only $26.7 \pm 1.59 \%$ of the $4 \mathrm{~T} 1$ cells exposed to S/C-W-LPNs passed through the membrane (Fig. 4c). This migration rate was dramatically lower than that measured for the $4 \mathrm{~T} 1$ cells subjected to C-WLPNs and S-W-LPNs. We also performed an invasion assay on a Matrigel-coated Transwell to determine the metastasis-promoting capacity of ECM barrier migration. After treatment with C-W-LPNs, S-W-LPNs, and
S/C-W-LPNs, $48.5 \pm 2.4 \%, 71.1 \pm 2.2 \%$, and $22.9 \pm 4.2 \%$ of the cells passed through the Matrigel (Fig. 4d, f).

\section{pW-LPN distribution in the rat intestine}

pW-LPN distribution assay in the rat intestine was performed to explore whether orally administered pHPMAnanoparticle associations could influence nanoparticle distribution in the jejunum in rats. Figure 5a show fluorescence microscopy images of jejunum cross-sections from rats fed with W-LPNs and pW-LPNs. One hour after the administration, all nanoparticles were observed in the jejunum. Compared with the W-LPNs, pW-LPNs had stronger green fluorescence signals and were, therefore, more widely distributed over the tissue surface. Moreover, the pW-LPNs were evenly distributed between the villi. Finally, the pW-LPNs more deeply penetrated the epithelia and intestinal cells than the W-LPNs.

The nanoparticle distributions in rat intestinal Peyer's patches was performed to evaluate the influence of the pHPMA-nanoparticle associations on alternative absorption routes. All nanoparticles were distributed in the a
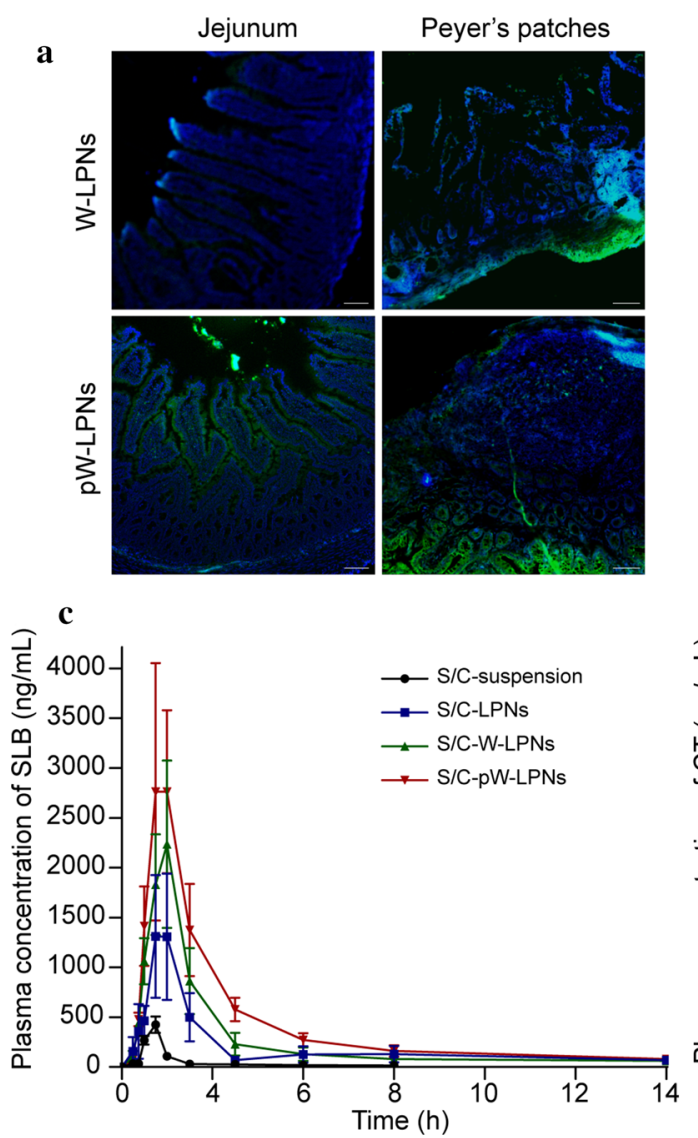

\section{b}

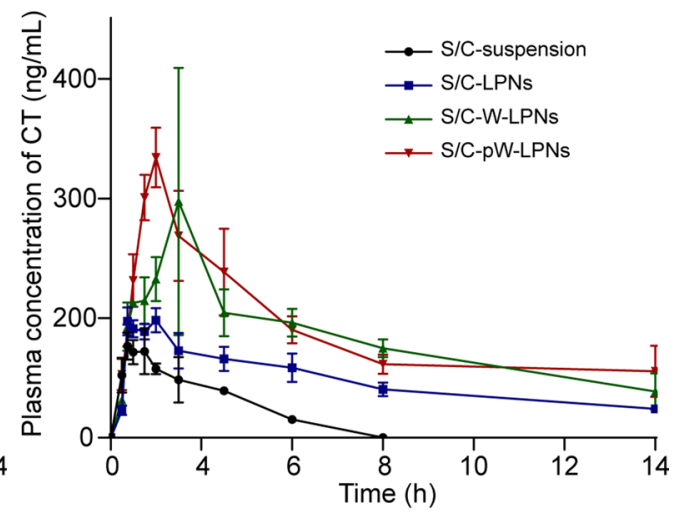

Fig. 5 a Typical distributions of W-LPNs and pW-LPNs in rat jejunum and typical particle absorption in Peyer's patches after oral gavage. (scale bar $=100 \mu \mathrm{m})$. b Quantitative analysis of particles in Peyer's patch tissue (mean \pm SD, $n=3$ ). c S/C-suspension, S/C-LPNs, S/C-W-LPNs, and S/C-pW-LPNs concentration-time curves for SLB (left) and CT (right) in rats following ig administration at $80 \mathrm{mg} / \mathrm{kg}\left(\mathrm{mean} \pm \mathrm{SD}, \mathrm{n}=5\right.$ ). ${ }^{* *} \mathrm{P}<0.001$ 
Peyer's patches, and the green fluorescence was stronger in the pW-LPN group than the W-LPN (Fig. 5a). One hour after oral gavage with pHPMA-nanoparticles, the absorption in the Peyer's patches markedly increased (Fig. 5b).

\section{Pharmacokinetics studies}

Plasma SLB and CT concentration-time profiles after oral administration of S/C-suspension, S/C-LPNs, S/CW-LPNs, and S/C-pW-LPNs are shown in Fig. 5c. Mean pharmacokinetic parameters are listed in Additional files 1: Tables S1 and S2. For the S/C-pW-LPNs, the plasma SLB and CT concentrations were substantially higher than other treatments. The area under the curve (AUC) of the S/C-pW-LPNs for SLB was 9,796.75 $\pm 846.76 \mu \mathrm{g}$ / L.h. This value was $15.9 \times, 1.5 \times$, and $1.13 \times$ higher than that measured for the S/C-suspension, S/C-LPNs, and S/C-W-LPNs, respectively. The AUC of S/C-pWLPNs for CT was $5019.36 \pm 483.16 \mu \mathrm{g} / \mathrm{L} \cdot \mathrm{h}$. This value was $6.48 \times, 1.70 \times$, and $1.05 \times$ higher than that determined for the S/C-suspension, S/C-LPNs, and S/CW-LPNs, respectively. S/C-pW-LPN MRT and $t_{1 / 2}$ for SLB were $16.50 \pm 2.63 \mathrm{~h}$ and $22.33 \pm 3.77 \mathrm{~h}$. These values were $4.34 \times$ and $5.43 \times$ higher than those calculated for the suspensions. S/C-pW-LPN MRT and $t_{1 / 2}$ for CT were $9.23 \pm 0.79 \mathrm{~h}$ and $10.40 \pm 5.56 \mathrm{~h}$. These values were $5.34 \times$ and $3.28 \times$ higher than those calculated for the suspensions. The relative bioavailabilities of SLB and CT in the S/W-pW-LPNs were $15.5 \times$ and $11.4 \times$ higher than those in the suspensions, respectively. Hence, the pWLPNs enhanced oral bioavailability.

\section{Anti-metastasis studies in vivo}

The ability of S/C-W-LPNs to inhibit tumor growth was evaluated in nude mice induced with $4 \mathrm{~T} 1$ breast cancer cells. Figure $6 \mathrm{a}$ shows that the S/C-LPN-treated mice exhibited smaller tumor volumes than those administered S-LPN and C-LPN. However, they did not significantly differ from each other or the saline treatment. All treatments failed to inhibit rapid tumor growth. Nevertheless, tumor growth was comparatively slower in the S/C-pW-LPNs treatment throughout the trial period. Compared with the saline control, the S/C-pW-LPNstreated mice exhibited slower tumor growth progression. However, we observed no overall tumor regression (Fig. 6c). Although the S/C-pW-LPNs had greater antitumor efficacy than the other formulations, none of them had strong enough tumor growth suppression ability to affect tumor regression. Figure $6 \mathrm{~b}$ demonstrates that none of the aforementioned preparations caused any critical weight loss in the mice.
As the nanoparticle formulations substantially inhibited 4T1 cell migration and invasion in vitro, their suppression efficacy was examined in a 4T1 lung metastasis model in vivo. As a result, excised lung tissue morphology was observed. Figure $6 \mathrm{~d}$ reveals dramatic surface pulmonary metastasis in the saline control group. The results of the histopathological analysis were consistent with the morphological observation. Hematoxylin and eosin $(\mathrm{H} \& \mathrm{E})$ staining of the lung tissue disclosed $>10$ metastases. Unlike their limited efficacy at suppressing breast cancer tumor growth, S/C-LPNs and S/C-pWLPNs considerably reduced the number of lung metastasis foci (Fig. 6e). However, S/C-pW-LPNs exhibited superior anti-metastasis activity. Lung tissue treated with S/C-pW-LPNs presented with smooth surfaces and minimal metastatic foci. H\&E staining demonstrated that S/C-pW-LPNs more strongly suppressed the formation of metastatic foci in lung tissue than other treatments.

An immunoblot assay was conducted to elucidate the molecular mechanism of S/C-pW-LPN anti-metastasis action. Based on previous pharmacological studies of SLB and CT anti-metastasis, and the roles of specific indicators in inducing breast cancer metastasis in tumor microenvironments, CD31, MMP-9, and TGF- $\beta 1$ expression were detected in breast cancer and lung metastasis tissue. As shown in Fig. 6f, the expression levels of CD31, MMP-9, and TGF- $\beta 1$ in the tumor tissues of the mice treated with saline were higher than those in the tumor tissues of the mice treated with S/C-pW-LPNs. Lung tissue treated with S/C-pW-LPNs did not express CD31, and only sporadically expressed TGF- $\beta 1$ and MMP-9 at the cellular level, at lower levels than the control group. Hence, the anti-metastatic action of S/C-pW-LPNs may have comprised the reduction in tumor cell adhesion to endothelial cells, inhibition of tumor angiogenesis, and attenuation of EMT.

\section{Discussion}

In our previous study, we tested WGA-LPNs coated with hydrophilic PEG as an oral carrier and found that its mucus penetration, absorption, and antitumor efficacy were strong [23]. Functional polymer-lipid hybrid nanoparticle associated with a detachable hydrophilic polymer was developed in this study for the oral co-delivery of two active ingredients derived from traditional Chinese medicine (TCM) known to suppress breast cancer pulmonary metastasis. The pHPMA promoted WGA-LPN mucus penetration in vitro and in vivo. The hydrophilic coating on PEGylated WGA-LPNs enabled the dissociation of pHPMA from the nanoparticles and permitted WGA-mediated target cell uptake without compromising the interaction between WGA-LPNs and intestinal enterocytes. Mucin binding may alter the WGA-LPN 


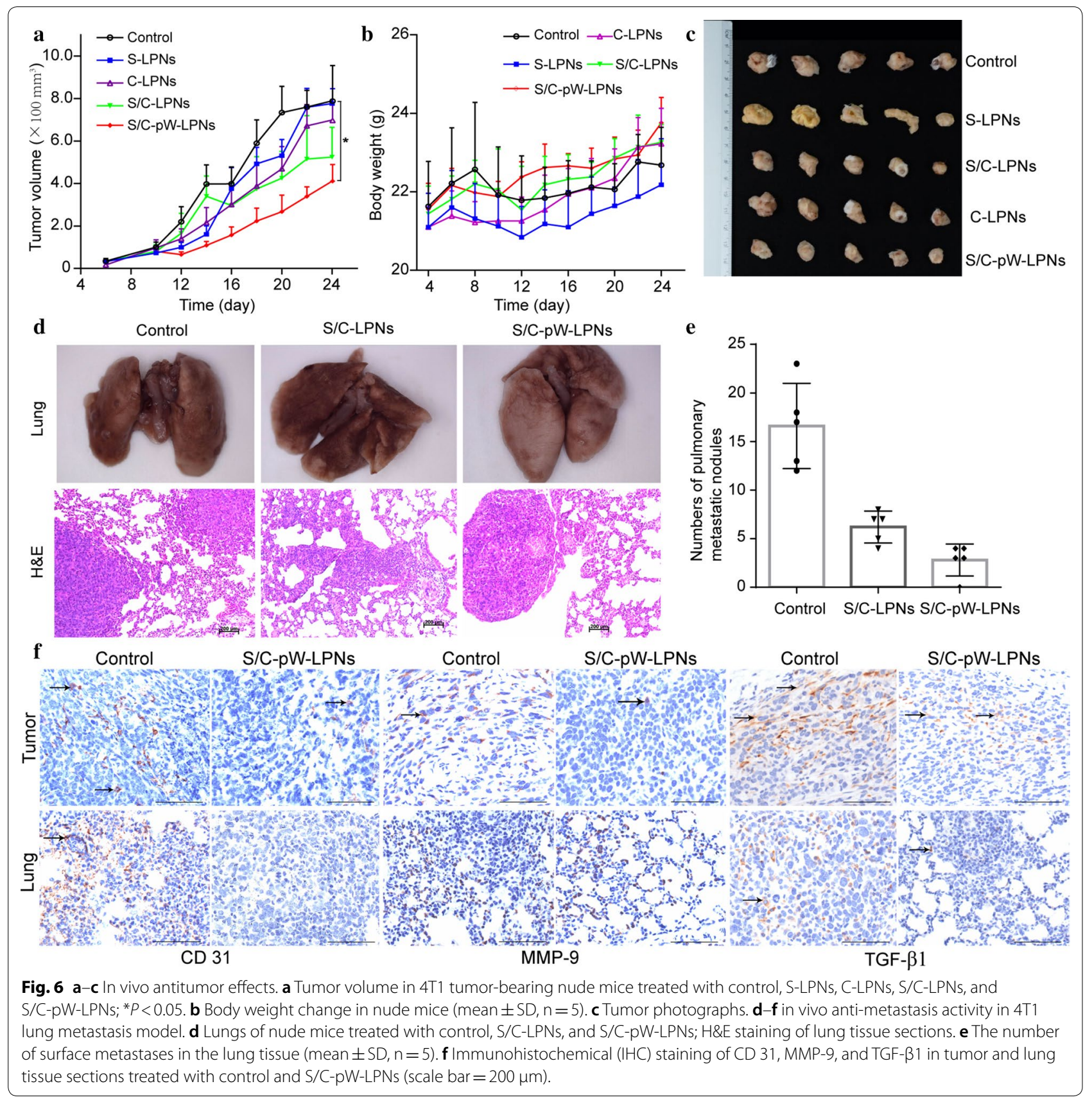

endocytosis pathway. The nanodispersion systems developed here substantially improved SLB and CT bioavailability, enhanced their mean retention times in vivo, and augmented the delivery of a therapeutically effective drug. WGA-LPNs loaded with SLB and CT only weakly inhibited breast cancer tumor growth. However, oral administration of this complex to 4T1 tumor-bearing nude mice strongly inhibited pulmonary metastasis by downregulating CD31, MMP-9, and TGF- $\beta 1$ in the tumor tissue. Therefore, the treatment mentioned above suppresses breast cancer metastasis by inhibiting factors that promote cancer progression in the tumor microenvironment.

Efficient nanocarrier penetration through the mucus layer and enterocyte uptake and transport are prerequisites for the robust anti-metastasis effect of orally administered drugs. WGA may target NAG and sialic acid on the surfaces of enterocytes and microfold cells and induce receptor-mediated endocytosis. However, WGA-LPNs encountered at least two obstacles before they arrive 
at the target site. First, interactions between the hydrophobic surfaces of the nanoparticles and the hydrophobic regions of the mucus hindered WGA-LPN diffusion through the mucus layer. Second, specific glycosylated components in the mucus layer trapped WGA-LPNs. Therefore, we coated the WGA-LPNs with pHPMA to protect the nanoparticles as they penetrated the mucus layer and expose the WGA functional group when the nanoparticles reach the enterocyte surfaces. The association between pHPMA and WGA-LPNs increased the hydrophilic radius of the dispersion systems, augmented surface hydrophilicity, and facilitated nanoparticle penetration through the mucus. Based on these results, an in vitro mucus penetration test and an in vivo rat jejunum distribution assay were conducted. The pW-LPNs markedly enhanced nanoparticle diffusion through the mucus because there was a low affinity between the pWLPNs and the mucin. Moreover, pHPMA detachment from the WGA-LPNs before endocytosis was visualized. This mechanism had a dramatic impact on intestinal absorption and the subsequent biological behavior of the nanoparticles.

Mucins are the main components of mucus. They are dynamically secreted to the apical surface by goblet and Paneth cells. In our previous work, we reported that the cellular uptake of WGA-LPN-mucin complex was superior to that of WGA-LPNs alone [23]. Thus, when WGALPNs near the cell membrane encounter new mucin, they interact with it and the resultant complex influences nanoparticle endocytosis. Here, we sought to establish whether mucin-WGA-LPN binding depends on mucin concentration and determine its effects on the endocytosis pathways. It was found that relatively lower mucin concentrations considerably enhanced cellular nanoparticle uptake, whereas higher mucin concentrations did not. One possible explanation for this discrepancy is the large molecular size and spatial structure of mucin. The concentration of mucin influences its aggregation and physical properties [28]. At lower mucin concentrations tested here, spaces were available around the W-LPN surfaces for mucin to bind and form complexes, get recognized by enterocytes, and induce endocytosis. Mucin that is adsorbed to nanoparticle surfaces forms coronas and aggregates [29]. The resultant alterations in surface morphology may also enhance cellular uptake.

Further investigation is required to elucidate the surface changes that occur when W-LPNs and mucins interact. At higher mucin concentrations, there was little room for additional mucin, and the unbound excess mucin either self-aggregated or clustered with other components in the mucus and increased viscosity. Mucin binding on the surface might enhance cellular uptake. In contrast, excess mucin could form large aggregates, increase ambient viscosity, and obstruct nanoparticle access to the cell surface. The outcome of these two opposing processes is that there is no significant net alteration in cellular nanoparticle uptake.

The influences of mucin on the endocytosis pathway are shown in Fig. 3d. In the presence of $\mathrm{NaN}_{3}$, there was no substantial difference in nanoparticles with or without mucins because $\mathrm{NaN}_{3}$ reduced the available metabolic energy [30]. Nystatin is a lipid raft/caveola inhibitor and disruptor. Lipid rafts are microdomains consisting of dynamic protein-lipid assemblies. The lipids and proteins can be associated via hydrophobic membrane-spanning sequences, transmembrane domains, hydrophobic regions, and protein-protein and protein-lipid interactions [31, 32]. Therefore, mucin bound with nanoparticles might facilitate W-LPN endocytosis via lipid rafts, reduce the inhibitory action of nystatin, and increase cellular nanoparticle uptake compared to that observed with the mucin-free treatment. Macropinocytosis forms large vesicles that contain the nanoparticles [33]. The endocytotic mechanism of macropinocytosis is a lipid raft/caveolae-dependent, clathrin-independent pathway. Mucin bound with nanoparticles could also facilitate cellular WGA-LPN uptake by macropinocytosis. Overall, mucin bound with W-LPNs may interact with the domain associated with lipid raft/caveolae and the macropinocytosis pathway.

The natural products in medicinal herbs and/or their derivatives are promising prophylactic and therapeutic approaches to breast cancer metastasis. They are antimetastatic via multiple targets and pathways [34-36]. SLB regulates EMT, protease activation, and other processes [37, 38]. CT inhibits tumor cell invasion, metastasis, and proliferation and promotes tumor cell apoptosis $[15,39]$. Recent nanocarrier studies focused on the antimetastatic action of SLB alone and SLB combined with chemotherapeutic and/or photothermal agents [40-42]. Breast cancer metastasis is a complex process involving multiple steps and cytokines. Thus, it was expected that SLB/CT co-administration would enhance the overall anti-metastasis effect via an interaction between two different modes of action. Relative to SLB combined with other chemotherapeutic agents, SLB/CT co-delivery was expected to enhance the inhibition of metastasis without increasing toxicity or adverse reactions. LPNs co-loaded with SLB/CT were relatively more effective than single drug-loaded LPNs at inhibiting 4T1 cell migration and invasion. For the in vivo anti-metastasis assay on orally administered nanoparticles in nude mice bearing 4T1 tumors, SLB- or CT-loaded LPNs were not effective in inhibiting tumor growth. This result was consistent with that of a previous report [40]. SLB/CT-co-loaded LPNs more potently inhibited tumor growth than nanoparticles 
charged with either SLB or CT alone. Nevertheless, an increase in primary tumor size is not strictly correlated with metastasis [43]. A fundamental objective of the present study was to inhibit breast cancer metastasis safely and effectively. The LPNs co-loaded with SLB/CT substantially inhibited breast cancer metastasis. However, this effect was markedly more substantial with SLB/CTco-loaded pW-LPNs than it was with LPNs co-loaded with SLB/CT. Tumor cells have been a primary focus of cancer research over the past four decades. However, there is emerging evidence that alterations within the tumor microenvironment, complex cell mixtures, secretory and cell surface proteins, and ECM play essential roles in tumor progression, metastasis, and therapeutic response [44, 45]. For these reasons, one target of the present study was the tumor microenvironment rather than cytotoxic therapies.

To understand how oral nanoparticles influence the tumor microenvironment, we investigated anti-metastasis in terms of angiogenesis, EMT, and ECM remodeling via immunohistochemistry (IHC) and detection of the CD31, TGF- $\beta 1$, and MMP-9 expression levels. CD31 expression was quantified to determine microvessel density [46]. TGF- $\beta 1$ was measured to assess EMT [47]. MMP-9 was evaluated because it regulates ECM degradation, which, in turn, facilitates breast cancer invasion and migration [48]. Upregulated MMP-9 is associated with the onset of metastases and poor prognosis. Compared with the control group, the three aforementioned biomarkers were dramatically downregulated in the tumor tissues and lungs of the pW-LPNs treatment group. Therefore, reductions in vascular density, EMT, and ECM degradation could all contribute to the anti-metastasis action of pW-LPNs. In this study, the improved anti-metastasis effect of S/C-pW-LPNs was shown in comparison with S/C- LPNs. Further studies are required to reveal the superiority of S/C-pW-LPNs in anti-metastasis in comparison with other preparations or administration routes, such as co-administration of SLB and CT without nanoparticles, single drug-loaded pW-LPNs, and parenteral administration. Breast cancer metastasis is highly complex and involves numerous processes and bipotential molecular and cellular switches [49]. It remains to be determined whether pW-LPNs mediate alternate regulatory mechanisms such as crosstalk among MMP-9, VEGF, and other molecular targets.

We hope that the orally administered nanoparticle-natural plant product formulation developed here will clinically enhance anti-metastasis in breast cancer treatment, reduce toxicity and side effects, and improve patient compliance during therapy.

\section{Conclusions}

Here, we evaluated the effectiveness of an oral nanocarrier at delivering the two natural plant products, SLB and $\mathrm{CT}$, to inhibit breast cancer lung metastasis. The nanoparticle architecture improved SLB and CT mucus penetration, cellular uptake, and oral bioavailability. Enhanced SLB and CT uptake by target 4T1 cancer cells inhibited in vitro invasion and migration. An in vivo anti-metastasis study confirmed that these novel nanoparticles coloaded with SLB and CT inhibited lung metastasis in 4T1 breast cancer-bearing nude mice. Thus, SLB- and CT-coloaded pW-LPNs may be a practical and innovative treatment option for breast cancer lung metastasis.

\section{Materials and methods pW-LPN preparation and characterization}

W-LPNs were prepared according to a previously reported method [30]. Briefly, LPNs were obtained using a modified nanoprecipitation method. SLB, CT, and PLGA were dissolved in acetonitrile. Lipoid S100 and DSPE-PEG2000 were dissolved in ethanol and dispersed in deionized water at $65^{\circ} \mathrm{C}$. The organic phase was added to the aqueous phase, and the mixture was gently stirred for $2 \mathrm{~h}$. The acetonitrile was removed by rotary evaporation, and the dispersion was filtered using a $0.8-\mu \mathrm{m}$ membrane. WGA-DOPE was prepared using a previously reported method [30]. LPNs were then incubated with WGA-DOPE for $18 \mathrm{~h}$ and purified using Sepharose ${ }^{\mathrm{TM}} \mathrm{CL}-4 \mathrm{~B}$ to obtain W-LPNs. pW-LPNs were formed by incubating the W-LPN dispersion in pHPMA solution $(2.5 \mathrm{mg} / \mathrm{mL})$ for $2 \mathrm{~h}$. pHPMA was synthesized using a previously reported method [26]. Coumarin- 6 loaded nanoparticles were prepared using the same method with coumarin- 6 instead of drugs.

Particle size and zeta potential were measured using a Zetasizer Nano ZS90 (Malvern Instruments, Malvern, UK). Particle morphology was characterized by observation via TEM (JEM-2100F; JEOL Ltd., Tokyo, Japan). The conditions of the XRD analysis were as follows: Radiation source, $\mathrm{Cu} / \mathrm{K} \alpha$; working voltage, $40 \mathrm{kV}$; current, $100 \mathrm{~mA}$; scanning range, $2 \theta$ from $3^{\circ}$ to $50^{\circ}$; scanning speed, $8^{\circ} \%$ $\min$.

\section{Mucus penetration assay}

Mucus penetration was determined according to a previously reported method [22]. Schematic of this process is shown in Fig. 2a. Six hundred $\mu \mathrm{L}$ of mucus were placed in each 6-mm silicon tubes to a height of $30 \mathrm{~mm}$. Then, $100 \mu \mathrm{L}$ of COU-W-LPNs and COU-pW-LPNs was gently set on the mucus surfaces, and the tubes were sealed. The tubes were kept upright, gently shaken for $12 \mathrm{~h}$ at $37^{\circ} \mathrm{C}$, freeze-dried at $-80{ }^{\circ} \mathrm{C}$, and cut into 2 -mm-thick slices. 
Each slice was transferred to a centrifuge tube and sonicated in $200 \mu \mathrm{L}$ acetonitrile for $15 \mathrm{~min}$. The suspensions were centrifuged at $1800 \mathrm{~g}$ for $5 \mathrm{~min}$ at $4{ }^{\circ} \mathrm{C}$, the supernatants were withdrawn, and the fluorescence intensities were measured in a microplate reader (Synergy HT; BioTek, Winooski, VT, USA) at an excitation wavelength of $485 \mathrm{~nm}$ and an emission wavelength of $528 \mathrm{~nm}$.

In vitro penetration of pW-LPNs into HT29-MTX-E12 cell mucus was evaluated using confocal microscopy. HT29-MTX-E12 cells were seeded on a glass bottom culture dish at a density of $8 \times 10^{5}$ per plate. After 5 days of culture, the dual fluorescent-labeled nanoparticles were incubated together with the cells for $1 \mathrm{~h}$, washed thrice with phosphate-buffered saline (PBS), subjected to Hoechst33342 nuclear staining, and observed under TCS SP8 confocal system (Leica, Mannheim, Germany). Consecutive parallel $x y$-sections were used as focal planes along the $\mathrm{z}$-axis mode at $10-\mu \mathrm{m}$ intervals. Dual fluorescentlabeled pW-LPN composed of TRITC-labeled pHPMA and FITC-labeled W-LPNs, in which TRITC-labeled pHPMA and FITC-labeled WGA-DOPE were synthesized according to the existing procedure in the literature [50, 51].

\section{Nanoparticle tracking analysis}

QDs (CdSe/ZnS)-loaded W-LPNs and pW-LPNs were prepared as previously mentioned [23]. Chloroform was removed from QDs dispersion $(1 \mathrm{mg} / \mathrm{mL})$ under a nitrogen stream. After redispersion in $1 \mathrm{~mL}$ of acetonitrile and sonification at $100 \mathrm{~W}$ for $5 \mathrm{~min}$, they were added into the oil phase. Then, the remaining procedure was the same as W-LPNs and pW-LPNs preparation. CdSe/ ZnS-loaded W-LPNs or pW-LPNs were incubated with porcine mucus $(1: 6, \mathrm{v} / \mathrm{v})$ at $37^{\circ} \mathrm{C}$ for $0.5 \mathrm{~h}$. The mixtures were diluted with deionized water $(1: 10,000)$, and the particle concentrations and intensities were analyzed in a Nanosight NS300 (Malvern Instruments, Malvern, UK). Mucus-free samples were prepared by diluting CdSe/ $\mathrm{ZnS}$-loaded nanoparticles with deionized water.

\section{Cellular uptake}

Caco-2 and HT29-MTX-E12 cells were seeded in 96-well plates at a density of $10^{4}$ per well and cultured in highglucose Dulbecco's modified Eagle's medium (DMEM), containing $10 \%$ fetal bovine serum and $1 \%$ penicillinstreptomycin for 6 days. The cultures were equilibrated with Hanks' balanced salt solution (HBSS) at $37{ }^{\circ} \mathrm{C}$ for $30 \mathrm{~min}$, and the HBSS was replaced with DMEM containing equal volumes of the tested sample (containing coumarin-6, $1.5 \mu \mathrm{g} / \mathrm{mL}$ ). Coumarin-6-loaded nanoparticles (LPNs and W-LPNs) were dispersed in PBS until equal fluorescence intensities were achieved. Then mucin solution $(0.025 \% \mathrm{w} / \mathrm{v})$ or PBS was added. After
$1 \mathrm{~h}$ incubation, the cells were washed thrice with PBS and lysed using CelLyti M (Sigma-Aldrich, St Louis, MO, USA). Fluorescence intensities were detected using a microplate reader at $485 \mathrm{~nm}$ excitation and $525 \mathrm{~nm}$ emission. The mucus layer was removed from the cells by preincubation with $10 \mathrm{mM} \mathrm{N}$-acetyl-L-cysteine. The nanoparticle dispersions were combined with mucin solution, and the mixtures were gently stirred at $37^{\circ} \mathrm{C}$ for $3 \mathrm{~h}$ to elucidate the influence of mucin on cellular uptake. After ultrafiltration using Vivaspin 6.0 (MW1000KD, Sartorius Stedim Biotech SA, Aubagne, France) at $3000 \mathrm{~g}$ for 20 min at $20-25{ }^{\circ} \mathrm{C}$, the filtrate was collected, and cellular uptake was observed under a confocal laser scanning microscope. Nile Red and FITC were used to label the nanoparticles and mucin, respectively. The nanoparticles were incubated with FITC-mucin $(0.025 \%$ w/v) with gentle stirring at $37^{\circ} \mathrm{C}$ for $1 \mathrm{~h}$. The sample was purified using a $0.8-\mu \mathrm{m}$ nylon membrane filter and ultrafiltered using a Vivaspin 6.0 at $3000 \mathrm{~g}$ for $20 \mathrm{~min}$ at $20-25^{\circ} \mathrm{C}$. The sample was redispersed in PBS ( $\mathrm{pH} 7.4$ ). Caco-2 cells were seeded at a density of $5 \times 10^{4}$ well $^{-1}$ and cultured overnight. Before the experiment, the culture medium was withdrawn, and the cells were incubated for $1 \mathrm{~h}$ in DMEM containing nanoparticles with or without mucin, washed thrice with PBS, fixed with $4 \%(v / v)$ paraformaldehyde (PFA), subjected to 4',6-diamidino-2-phenylindole (DAPI) staining for $15 \mathrm{~min}$, and washed thrice with PBS. Cells were observed under a Leica TCS SP8 confocal system (Leica Microsystems, Wetzlar, Germany).

\section{In vitro cell migration and invasion assay}

To evaluate cell migration, we plated $10^{5} 4 \mathrm{~T} 1$ cells in serum-free medium were plated in the top chamber of a Transwell. C-W-LPNs, S-W-LPNs, and S/C-W-LPNs $(5.0 \mu \mathrm{g} / \mathrm{mL} \mathrm{CT} ; 30 \mu \mathrm{g} / \mathrm{mL}$ SLB$)$ were dispersed into the top chamber. To evaluate cell invasion, we plated $10^{5}$ 4T1 cells in serum-free medium in the top chamber of a Transwell pre-coated with Matrigel (BD Biosciences, Franklin Lakes, NJ, USA). Nanoparticles identical to those used in the cell migration study were dispersed into the top chamber. Complete medium was added as a chemoattractant to the lower chamber. After incubation for $24 \mathrm{~h}$ at $37^{\circ} \mathrm{C}$, cells failing to migrate to or invade the upper chamber were carefully removed with a cotton swab. Cells that traversed the membrane were fixed with $90 \%(\mathrm{v} / \mathrm{v})$ ethanol, stained with Hematoxylin-eosin, and observed under the microscope (Leica DMi1, Leica, Mannheim, Germany).

\section{In vivo bioavailability}

Sprague-Dawley rats (female) each weighing $220 \pm 20 \mathrm{~g}$ were randomly assigned to four groups $(n=5)$. S/C-suspension, S/C-LPNs, S/C-W-LPNs, and S/C-pW-LPNs 
were administered by oral gavage, containing equivalent doses of SLB and CT $(80 \mathrm{mg} / \mathrm{kg})$. The S/C-suspension was prepared by dissolving equimolar SLB and CT in CMC-Na dispersion. Four hundred $\mu \mathrm{L}$ of blood samples were withdrawn at $30 \mathrm{~min}, 45 \mathrm{~min}, 60 \mathrm{~min}, 90 \mathrm{~min}, 2 \mathrm{~h}$, $3 \mathrm{~h}, 5 \mathrm{~h}, 8 \mathrm{~h}, 12 \mathrm{~h}$, and $24 \mathrm{~h}$ and placed in heparinized tubes. For one period of $24 \mathrm{~h}$, two animals were used to withdraw the blood samples, one for the first five time points, and the other is for the remaining five time points. After centrifugation at $3500 \mathrm{~g}$ and $4{ }^{\circ} \mathrm{C}$ for $10 \mathrm{~min}$, the plasma was separated. SLB in plasma was determined according to a previously reported method [52]. The plasma samples were treated with $\beta$-glucuronidase to liberate SLB. The free SLB was extracted using tertbutyl methyl ether, and the organic layer was evaporated with a nitrogen stream. Details of SLB and CT determination are described in the Supporting Information. The pharmacokinetic parameters were obtained using a non-compartmental model in Drugs and Statistics v. 2.0 (Mathematical Pharmacology Professional Committee of China).

\section{In vivo antitumor efficiency}

Female BALB/c nude mice aged 5-6 weeks were randomly assigned to four groups $(n=5)$. Each mouse was injected with $4 \times 10^{5} 4 \mathrm{~T} 1$ cells in the second pair of mammary pads. After 3 days, the mice were orally administered saline, S-LPNs, C-LPNs, S/C-LPNs, or S/C$\mathrm{pW}-\mathrm{LPNs}$ containing equivalent doses of SLB and CT $(80 \mathrm{mg} / \mathrm{kg})$. The treatments were applied every 2 days. Tumor volume obtained using calipers and body weight were measured every second day. Tweenty three days after the first administration, all mice were sacrificed, the tumors and lung tissues were excised and photographed, and the pulmonary metastases were counted. H\&E staining was performed on the lung tissues for histological examination $(\mathrm{n}=3)$. Immunohistochemical (IHC) analysis was conducted to measure the CD31, TGF- $\beta 1$, and MMP-9 expression levels in the tumor and lung tissues. Tumor and lung tissues were fixed in formalin, embedded in paraffin, cut into $5 \mu \mathrm{m}$ thick sections using a microtome (Leica CM1510, Mannheim, Germany), baked at $60{ }^{\circ} \mathrm{C}$, deparaffinized in xylene, and rehydrated in a graded ethanol series and distilled water. Antigens were retrieved using high temperature-pressure repair with Tris-ETA buffer. After four rinses with $\mathrm{PBS}$, the sections were blocked with hydrogen peroxide $\left(\mathrm{H}_{2} \mathrm{O}_{2}\right)$, washed $4 \times$ with PBS, incubated with goat serum for $40 \mathrm{~min}$, and incubated with rabbit monoclonal anti-MMP-9 antibody (ab22802; Abcam, Cambridge, UK), rabbit monoclonal anti-CD31 antibody (ab182981; Abcam, Cambridge, UK), and rabbit monoclonal TGF$\beta 1$ antibody (ab215715; Abcam, Cambridge, UK) in a dark chamber at $4{ }^{\circ} \mathrm{C}$ overnight. The sections were then washed in PBS, incubated with horseradish peroxidase (HRP)-goat anti-rabbit secondary antibody (MaxVision ${ }^{\mathrm{TM}}$ HRP-polymer anti-rabbit IHC kit, Fuzhou Maixin Biotech. Co. Ltd., Fuzhou, China) of the appropriate species at $37{ }^{\circ} \mathrm{C}$ for $30 \mathrm{~min}$ and washed with PBS. Staining was performed with the chromogenic substrate 3,3'-diaminobenzidine (DAB). The sections were then rinsed under running water for $10 \mathrm{~min}$, counterstained with hematoxylin, and washed under running water. After dehydration with ethanol, the sections were mounted on glass slides and visualized under a microscope.

\section{Statistical analysis}

Data are represented as mean \pm standard deviation (SD). One-way analysis of variance with Tukey's post-test was used for data comparisons. $\mathrm{P}<0.05$ was considered statistically significant.

\section{Supplementary information}

Supplementary information accompanies this paper at https://doi. org/10.1186/s12951-020-00638-x.

Additional file 1: Functional oral nanoparticles for delivering silibinin and cryptotanshinone against breast cancer lung metastasis.

\section{Abbreviations}

AUC: Area under the curve; CCK-8: Cell counting kit 8; CD31: Cluster of differentiation 31; CLSM: Confocal laser scanning microscopy; CT: Cryptotanshinone; DAB: 3,3'-diaminobenzidine; DAPI: 4',6-diamidino-2-phenylindole; DMEM: Dulbecco's modified Eagle's medium; ECM: Extracellular matrix; EMT: Epithelial-to-mesenchymal transition; FITC: Fluorescein isothiocyanate; H\&E: Hematoxylin and eosin; HBSS: Hanks' balanced salt solution; $I C_{50}$ : Half-maximal inhibitory concentration; HRP: Horseradish peroxidase; IHC: Immunohistochemistry; LPN: Lipid-polymer nanoparticles; MMP-9: Matrix metallopeptidase 9; MRT: Mean residence time; NAG: N-acetyl-D-glucosamine; PBS: Phosphatebuffered saline; PEG: Polyethylene glycol; PFA: Paraformaldehyde; pHPMA: Poly-N-(2-hydroxypropyl) methacrylamide; QD: Quantum dot; SLB: Silibinin; $\mathrm{t}_{1 / 2}$ : Half-life; TCM: Traditional Chinese medicine; TEM: Transmission electron microscopy; TGF- $\beta 1$ : Transforming growth factor beta 1; TRITC: Tetramethylrhodamine; VEGF: Vascular endothelial growth factor; WGA: Wheat germ agglutinin; XRD: X-ray powder diffraction.

\section{Authors' contributions}

$Y L$ and XX conducted preparation and characterization of the nanoparticles, in vivo bioavailability and antitumor efficiency studies; XX and XH performed in vitro mucus penetration assay; JS and JS performed nanoparticle tracking analysis experiments, and in vitro cell uptake, migration and invasion; XX, HC, $\mathrm{YH}$ and ZW performed in vivo bioavailability studies and pharmacodynamic study. NF and YL supervised the study. All authors read and approved the final manuscript.

\section{Funding}

This work was supported by the National Natural Science Foundation of China (No. 81773913, No. 81303232).

Availability of data and materials

All data generated and analyzed in this study are included in this manuscript.

Ethics approval and consent to participate

All the animal studies were approved by the animal ethics committee of the Institutional Animal Care and Use Committee, Shanghai University of TCM. 


\section{Consent for publication}

All authors agree to publication.

\section{Competing interests}

The authors report no competing interests.

Received: 26 March 2020 Accepted: 16 May 2020

Published online: 30 May 2020

\section{References}

1. Steeg PS. Targeting metastasis. Nat Rev Cancer. 2016;16:201-18.

2. Massagué J, Obenauf AC. Metastatic colonization by circulating tumour cells. Nature. 2016;529:298-306.

3. Gao D, Du J, Cong L, Liu Q. Risk factors for initial lung metastasis from breast invasive ductal carcinoma in stages I-III of operable patients. Jpn J Clin Oncol. 2009:39:97-104

4. Xu H, Hu M, Liu M, An S, Guan K, Wang M, Li L, Zhang J, Li J, Huang L. Nano-puerarin regulates tumor microenvironment and facilitates chemoand immunotherapy in murine triple negative breast cancer model Biomaterials. 2020;235:119769.

5. Ribeiro Franco PI, Rodrigues AP, de Menezes LB, Pacheco Miguel M. Tumor microenvironment components: allies of cancer progression. Pathol Res Pract. 2020;216:152729.

6. Liu JJ, Chen Q, Feng LZ, Liu Z. Nanomedicine for tumor microenvironment modulation and cancer treatment enhancement. Nano Today. 2018;21:55-73.

7. Deep G, Agarwal R. Targeting tumor microenvironment with silibinin: promise and potential for a translational cancer chemopreventive strategy. Curr Cancer Drug Targets. 2013;13:486-99.

8. Apaya MK, Chang MT, Shyur LF. Phytomedicine polypharmacology: cancer therapy through modulating the tumor microenvironment and oxylipin dynamics. Pharmacol Ther. 2016;162:58-68.

9. Deep G, Agarwal R. Antimetastatic efficacy of silibinin: molecular mechanisms and therapeutic potential against cancer. Cancer Metastasis Rev. 2010;29:447-63.

10. Kim S, Han J, Kim JS, Kim JH, Choe JH, Yang JH, Nam SJ, Lee JE. Silibinin suppresses EGFR ligand-induced CD44 expression through inhibition of EGFR activity in breast cancer cells. Anticancer Res. 2011;31:3767.

11. Lazzeroni M, Guerrieri-Gonzaga A, Gandini S, Johansson H, Serrano D, Cazzaniga M, Aristarco V, Puccio A, Mora S, Caldarella P, Pagani G, Pruneri G, Riva A, Petrangolini G, Morazzoni P, DeCensi A, Bonanni B. A Presurgical study of oral silybin-phosphatidylcholine in patients with early breast cancer. Cancer Prev Res. 2016;9:89-95.

12. Avila-Carrasco L, Majano P, Sánchez-Toméro JA, Selgas R, LópezCabrera M, Aguilera A, González Mateo G. Natural plant compounds as modulators of epithelial-to-mesenchymal transition. Front Pharmacol. 2019;10:715.

13. Liu XM, Pan LL, Liang JL, Li JH, Wu SH. Cryptotanshinone inhibits proliferation and induces apoptosis via mitochondria-derived reactive oxygen species involving FOXO1 in estrogen receptor-negative breast cancer Bcap37 cells. RSC Adv. 2016:27:22232-43.

14. Li S, Wang H, Hong L, Liu W, Huang F, Wang J, Wang P, Zhang X, Zhou J. Cryptotanshinone inhibits breast cancer cell growth by suppressing estrogen receptor signaling. Cancer Biol Ther. 2015;16:176-84.

15. Zhou J, Xu XZ, Hu YR, Hu AR, Zhu CL, Gao GS. Cryptotanshinone induces inhibition of breast tumor growth by cytotoxic CD4 + T cells through the JAK2/STAT4/perforin pathway. Asian Pac J Cancer Prev. 2014;15:2439-45.

16. Park IJ, Kim MJ, Park OJ, Choe W, Kang I, Kim SS, Ha J. Cryptotanshinone induces ER stress-mediated apoptosis in HepG2 and MCF7 cells. Apoptosis. 2012;17(3):248-57.

17. Thanki K, Gangwal RP, Sangamwar AT, Jain S. Oral delivery of anticancer drugs: challenges and opportunities. J Control Release. 2013;170(1):15-40

18. Mei L, Zhang Z, Zhao L, Huang L, Yang XL, Tang J, Feng SS. Pharmaceutical nanotechnology for oral delivery of anticancer drugs. Adv Drug Deliv Rev. 2013:65(6):880-90.

19. Luo C, Sun J, Du YQ, He ZG. Emerging integrated nanohybrid drug delivery systems to facilitate the intravenous-to-oral switch in cancer chemotherapy. J Control Release. 2014;176:94-103.
20. Qin JJ, Wang W, Sarkar S, Zhang R. Oral delivery of anti-MDM2 inhibitor SP141-loaded FCRn-targeted nanoparticles to treat breast cancer and metastasis. J Control Release. 2016:237:101-14.

21. Cao HQ, Zhang ZW, Zhao S, He XY, Yu HJ, Yin Q, Zhang ZP, Gu WW, Chen LL, Li YP. Hydrophobic interaction mediating self-assembled nanoparticles of succinobucol suppress lung metastasis of breast cancer by inhibition of VCAM-1 expression. J Control Release. 2015;205:162-71.

22. Dünnhaupt S, Barthelmes J, Hombach J, Sakloetsakun D, Arkhipova V Bernkop-Schnürch A. Distribution of thiolated mucoadhesive nanoparticles on intestinal mucosa. Int J Pharm. 2011;408(1-2):191-9.

23. Liu Y, Liu JG, Liang J, Zhang MY, Li Z, Wang Z, Dang BL, Feng NP. Mucosal transfer of wheat germ agglutinin modified lipid-polymer hybrid nanoparticles for oral delivery of oridonin. Nanomedicine. 2017;13(7):2219-29.

24. Liu M, Zhang J, Zhu X, Shan W, Li L, Zhong JJ, Zhang ZR, Huang Y. Efficient mucus permeation and tight junction opening by dissociable "mucusinert" agent coated trimethyl chitosan nanoparticles for oral insulin delivery. J Control Release. 2016;222:67-77.

25. Yang JY, Jindrich K. Design of smart HPMA copolymer-based nanomedicines. J Control Release. 2016;240:9-23.

26. Liu Y, Jiang ZF, Hou XF, Xie XX, Shi JP, Shen JY, He YZ, Wang Z, Feng NP. Functional lipid polymeric nanoparticles for oral drug delivery: rapid mucus penetration and improved cell entry and cellular transport. Nanomedicine. 2019;21:102075.

27. Kou LF, Sun J, Zhai YL, He ZG. The endocytosis and intracellular fate of nanomedicines: implication for rational design. Asian J Pharm Sci. 2013;8:1-10.

28. Bansil R, Turner BS. Mucin structure, aggregation, physiological functions and biomedical applications. Curr Opin Colloid Interface Sci. 2006:11(2-3):164-70.

29. Yang D, Liu DC, Qin MM, Chen BL, Song SY, Dai WB, Zhang H, Wang $X Q$, Wang $Y G$, He $B$, Tang $X$, Zhang $Q$. Intestinal mucin induces more endocytosis but less transcytosis of nanoparticles across enterocytes by triggering nanoclustering and strengthening the retrograde pathway. ACS Appl Mater Interfaces. 2018;10(14):11443-56.

30. Liu Y, Zhao YQ, Liu JG, Zhang MY, Yu ML, Feng NP. Wheat germ agglutinin modification of lipid-polymer hybrid nanoparticles: enhanced cellular uptake and bioadhesion. RSC Adv. 2016;6(42):36125-35.

31. Lucero HA, Robbins PW. Lipid rafts-protein association and the regulation of protein activity. Arch Biochem Biophys. 2004;426(2):208-24.

32. Ito $\mathrm{Y}$, Honda $\mathrm{A}$, Igarashi M. Glycoprotein M6a as a signaling transducer in neuronal lipid rafts. Neurosci Res. 2018;128:19-24.

33. Patel S, Kim J, Herrera M, Mukherjee A, Kabanov AV, Sahay G. Brief update on endocytosis of nanomedicines. Adv Drug Deliv Rev. 2019;144:90-111.

34. Salehi B, Varoni EM, Sharifi-Rad M, Rajabi S, Zucca P, Iriti M, Sharifi-Rad J. Epithelial-mesenchymal transition as a target for botanicals in cancer metastasis. Phytomedicine. 2019;55:125-36.

35. Gu HF, Mao XY, Du M. Prevention of breast cancer by dietary polyphenols-role of cancer stem cells. Crit Rev Food Sci Nutr. 2020;60(5):810-25.

36. Avtanski D, Poretsky L. Phyto-polyphenols as potential inhibitors of breast cancer metastasis. Mol Med. 2018;24:29.

37. Byun HJ, Darvin P, Kang DY, Sp N, Joung YH, Park JH, Kim SJ, Yang YM. Silibinin downregulates MMP2 expression via Jak2/STAT3 pathway and inhibits the migration and invasive potential in MDA-MB-231 cells. Oncol Rep. 2017;37:3270-8.

38. Mahmoodi N, Motamed N, Paylakhi SH. The comparison of the effects of silybin and silybin-phosphatidylcholine on viability and ESR expression in human breast cancer T47D cell line. Cell J. 2014;16:299-308.

39. Chen L, Wang HJ, Xie W, Yao Y, Zhang YS, Wang H. Cryptotanshinone inhibits lung tumorigenesis and induces apoptosis in cancer cells in vitro and in vivo. Mol Med Rep. 2014:9:2447-52

40. Xu P, Yin Q, Shen J, Chen L, Yu H, Zhang Z, Li Y. Synergistic inhibition of breast cancer metastasis by silibinin-loaded lipid nanoparticles containing TPGS. Int J Pharm. 2013;454:21-30.

41. Dong XY, Lang TQ, Yin Q, Zhang PC, Li YP. Co-delivery of docetaxel and silibinin using $\mathrm{pH}$-sensitive micelles improves therapy of metastatic breast cancer. Acta Pharmacol Sin. 2017;38:1655-62.

42. Sun HP, Su JH, Meng QS, Yin Q, Zhang ZW, Yu HJ, Zhang PC, Wang SL, Li YP. Silibinin and indocyanine green-loaded nanoparticles inhibit the 
growth and metastasis of mammalian breast cancer cells in vitro. Acta Pharmacol Sin. 2016;37:941-9.

43. Hosseini H, Obradović MMS, Hoffmann M, Harper KL, Sosa MS, WernerKlein M, Nanduri LK, Werno C, Ehrl C, Maneck M, Patwary N, Haunschild G, Gužvić M, Reimelt C, Grauvogl M, Eichner N, Weber F, Hartkopf AD, Taran FA, Brucker SY, Fehm T, Rack B, Buchholz S, Spang R, Meister G, AguirreGhiso JA, Klein CA. Early dissemination seeds metastasis in breast cancer. Nature. 2016;540:552-8.

44. Mittal S, Brown NJ, Holen I. The breast tumor microenvironment: role in cancer development, progression and response to therapy. Expert Rev Mol Diagn. 2018;18:227-43.

45. Place AE, Jin Huh S, Polyak K. The microenvironment in breast cancer progression: biology and implications for treatment. Breast Cancer Res. 2011;13:227.

46. Wu X, Zhang Y, Pei Z, Chen S, Yang X, Chen Y, Lin D, Ma RZ. Methylseleninic acid restricts tumor growth in nude mice model of metastatic breast cancer probably via inhibiting angiopoietin-2. BMC Cancer. 2012;12:192.

47. Imamura T, Hikita A, Inoue Y. The roles of TGF-beta signaling in carcinogenesis and breast cancer metastasis. Breast Cancer. 2012;19:118-24.

48. Wang X, Lu H, Urvalek AM, Li T, Yu L, Lamar J, DiPersio CM, Feustel PJ, Zhao J. KLF8 promotes human breast cancer cell invasion and metastasis by transcriptional activation of MMP9. Oncogene. 2011;30:1901-11.
49. Zhuang X, Zhang H, Hu G. Cancer and microenvironment plasticity: double-edged swords in metastasis. Trends Pharmacol Sci. 2019;40:419-29.

50. Shan W, Zhu X, Liu M, Li L, Zhong J, Sun W, et al. Overcoming the diffusion barrier of mucus and absorption barrier of epithelium by self-assembled nanoparticles for oral delivery of insulin. ACS Nano. 2015;9:2345-56.

51. Zhang JB, Lv Y, Wang B, Zhao S, Tan MQ, Lv GJ, Ma XJ. Influence of microemulsion-mucin interaction on the fate of microemulsions diffusing through pig gastric mucin solutions. Mol Pharm. 2015;12:695-705.

52. Yin T, Zhang Y, Liu Y, Chen Q, Fu Y, Liang J, Zhou J, Tang X, Liu J, Huo M. The efficiency and mechanism of N-octyl-O, N-carboxymethyl chitosanbased micelles to enhance the oral absorption of silybin. Int J Pharm. 2018:536:231-40.

\section{Publisher's Note}

Springer Nature remains neutral with regard to jurisdictional claims in published maps and institutional affiliations.
Ready to submit your research? Choose BMC and benefit from:

- fast, convenient online submission

- thorough peer review by experienced researchers in your field

- rapid publication on acceptance

- support for research data, including large and complex data types

- gold Open Access which fosters wider collaboration and increased citations

- maximum visibility for your research: over 100M website views per year

At BMC, research is always in progress.

Learn more biomedcentral.com/submissions 